\title{
O CORPO INSÓLITO E A BIOPOLÍTICA EM TEXTOS DE MARIO BELLATIN
}

Ivana Teixeira Figueiredo Gund ${ }^{1}$

\begin{abstract}
Resumo: $\mathrm{O}$ artigo discute as relações políticas experienciadas pelos corpos apresentados como disformes ou diferentes, presentes nas obras Salón de Belleza (2005) e Los fantasmas del masajista (2006), de Mario Bellatin. São corpos enfermos, adornados, mutilados ou maquiados que fogem aos padrões estabelecidos e constituem-se em lugar de existência e de não adequação aos modelos impostos socialmente. A relação deles com a vida coletiva será território de reflexão sobre conceitos éticos e políticos. Essa condição dos corpos evidenciará a aproximação de determinadas vidas ao conceito de vida nua. A análise se fundamenta nos estudos sobre biopolítica e utiliza, como fundamentação teórica Michel Foucault (1999; 2008), Giorgio Agamben (2010), Georges Didi-Huberman (2011), Roberto Esposito (2010) e Achille Mbembe (2016).
\end{abstract}

Palavras-chaves: Literatura; Biopolítica; Corpo; Mario Bellatin.

\section{Introdução}

Grande parte dos textos do escritor mexicano contemporâneo Mario Bellatin são povoados por personagens cujos corpos destoam dos padrões impostos e reconhecidos de beleza, de saúde, de sexualidade, entre outros. Corpos que, no curso da vida coletiva não seriam legitimados e valorizados socialmente ou carregariam estereótipos que os relacionariam ao feio, ao grotesco, ao pecaminoso, projetando sobre eles a exposição de condições que, geralmente, engendram repulsa, piedade ou desaprovação social. No entanto, em textos de Bellatin, esses corpos insólitos ${ }^{2}$ se convertem em lugares de resistência às formas de poder ou ainda, pelo fato de não se adequarem a elas, são capazes de provocar um estranhamento que pode, pelo contraste enaltecido como diferença proposital e política, realçar uma indiferença

${ }^{1}$ Doutora em Estudos Literários pela UFMG; Mestre em Teoria Literária pela UFJF. Professora da Universidade do Estado da Bahia - Campus X.E-mail: ivanatfgund@gmail.com.

${ }^{2}$ Termo adjetivo ( $1^{\text {a }}$ classe) do latim insolitus, a, um: 1$)$ não acostumado, não afeito a; estranho, alheio a; 2) desusado, novo, insólito (SARAIVA, 2000, p. 618). O sentido aqui é usado, especialmente, como um corpo incomum, diferente do padrão, que causa estranhamento. 
ao poder. Em vista disso, suas personagens são seres que transitam em um espaço complexo e impreciso: por um lado, estão dentro de uma marginalização forçada; por outro lado, a insistência em continuar sobrevivendo funciona como uma afirmação de suas identidades e como um excesso que rompe as amarras do controle.

Por conseguinte, são corpos (bio)gráficos sem, de fato, uma grafia de si: não há detalhes de identificação, descrição das origens ou de referências das vidas prévias dessas personagens. No sentido em que suas materialidades (corpos) se tornam inscrições da exclusão, leem-se impressões, palavra aqui aplicada em camadas ampliadas de sentido, pois as diferenças se apresentam tanto na própria imagem corporal como também se transpõem como sensações e opiniões coletivamente construídas. Nesses corpos se veem a deficiência física, a doença, a mutilação, a ferida, a cicatriz, a homossexualidade, o exagero da maquiagem e dos adornos, entre outras provocações, estranhamentos, exposições. Todas essas marcas são camadas sobrepostas à pele social das personagens descritas por Bellatin. Ao revesti-las assim, elas revelam e denunciam o valor menor, o estereótipo ou a desqualificação de cada um, dentro das perspectivas do poder - o que poderia ser qualificado como resistência ao disciplinamento -, mas também se percebe uma neutralidade e/ou frieza diante do poder.

Pode-se inferir que a presença desses corpos nos textos de Bellatin - ao tomar a realidade para transformá-la pelo critério da verossimilhança - abre espaço de reflexão sobre as diversas formas de disciplina e classificação que se impõem aos seres em suas interrelações sociais.

Para a análise proposta, parte-se da reflexão sobre as esferas do controle social, compreendido por meio do conceito de biopolítica, termo ressignificado por Michel Foucault em 1979, no qual o filósofo discute um poder regulador que abarca e controla ramificações da vida humana, desde o nascimento até a morte dos sujeitos, interpondo-se nas mais diversas áreas do convívio social. Junto às ações de matar ou deixar viver discutidas por Foucault, acrescenta-se a questão da exclusão e inclusão na vida política e a transformação de certas formas de vida em vida nua, conforme Giorgio Agamben (2007); analisa-se o pensamento de Roberto Esposito quanto às categorias do código biopolítico e ao paradigma da imunização; insere-se nas análises das obras o conceito de necropolítica cunhado por Achille Mbembe (2016); e, posteriormente, pensa-se essas formas de vida, a um só tempo, excluídas e inseridas no contexto social, como sobreviventes, de acordo com o que propõe Georges Didi-Hebermann (2011), quando reflete sobre a sobrevivência dessas vidas, na qualidade de indivíduos que existem e, com sua existência, colocam-se à margem, como um incômodo social, por descontrolar a ordem e romper limites. Dessa forma, por esses caminhos teóricos, pode-se perceber que, fora da condição de assujeitados pelo poder que estabelece o que deve ser preservado e o que deve ser aniquilado - justificando-se, para isso, um suposto bem comum - esses seres diferentes do que se entente como normalidade e, consequentemente, seus corpos, tornam-se excluídos, rotulados como algo 
contagioso, imoral, ilegal, estética e perigosamente diferente, por serem a própria materialização do descontrole, das brechas que esse poder tanto deseja ocultar, ou seja, a contrapelo, essas presenças põem a nu formas de vida que atuam com a força de seu ser, em suas materialidades e em suas individualidades.

As obras literárias elencadas como corpus de análise serão duas novelas de Mario Bellatin - Salón de Belleza (2005) e Los fantasmas del masajista (2006) -, pois nelas se encontram personagens em cujas peles estão as marcas de sua condição à margem de um poder, contudo inseridas no cenário urbano contemporâneo. São aqueles que foram expelidos, retirados de sua pele social, mas são também aqueles que, por estarem vivos, representam um descontrole, um escape na normalização, por isso mesmo, um perigo à ordem e à disciplina a que devem ser submetidos os corpos que precisam ser dóceis e produtivos, se pensados por meio da perspectiva biopolítica. A exclusão, eliminação ou mutilação desses corpos/seres é denunciada nos textos como uma estratégia de limpeza social, padronização e manutenção do bem comum, ao mesmo tempo em que se enfatiza a interferência - até mesmo física - da técnica sobre os corpos controlados pela biopolítica. Também esses textos parecem sinalizar que a sobrevivência desses corpos pode ser compreendida como menosprezo ao poder político, uma vez que o fim do corpo sempre se coloca contra ao ordenamento da vida.

Antes, porém, cabem algumas ponderações sobre os conceitos basilares para a discussão sobre biopolítica, bem como a compreensão da literatura como lugar de reflexão para esses temas. Por isso, a princípio, parte-se da reflexão sobre termos como biopolítica, necropolítica, sobrevivência, entre outros, para se chegar às análises dos textos de Mario Bellatin.

\section{A vida controlada por padrões estéticos e éticos}

A vida humana dentro de um sistema social está sujeita às formas de poder que estabelecem mecanismos de controle exercido por diversos setores - governamental, midiático, econômico, médico, estético, entre outros - que visam organizar a convivência entre os seres, bem como sua condição de peça fundamental no sistema de produção e de consumo. Desse modo, os indivíduos dentro desses sistemas sociais são validados por sua adequação, atuação, capacidade de inclusão, especialmente, ao se pensar no que Michel Foucault conceitua como microfísica do poder dentro do sistema capitalista. Assim, as vidas humanas são disciplinadas pelas instituições sociais, pelas normas de comportamento, pelas noções de deveres e direitos. As ações, os dados pessoais, os interesses, os discursos e demais aspectos, que deveriam ser da ordem do individual, são vigiados constantemente e computados por estatísticas e algoritmos que induzem comportamentos e formas de pensar, a fim de potencializar a administração dos seres humanos e sua capacidade como peça dentro das engrenagens do poder. Dentro desse raciocínio, os corpos produtivos e dóceis podem ser pensados como mão de obra necessária. 
Por outro lado, os corpos indisciplináveis ou que apresentam incapacidades físicas e intelectuais são isolados, estigmatizados ou destinados ao descarte social por meio da marginalização ou da morte, mesmo que seja por modos de matar dissimulados ou, de certa forma, normalizados socialmente. Assim, a vida humana - no âmbito da convivência dentro dos sistemas sociais - é controlada por uma força ou poder conceituado por Foucault (2008) como biopolítica. Foucault situa historicamente esse poder ao dizer que:

\begin{abstract}
a maneira como se procurou, desde o século XVIII, racionalizar os problemas postos a prática governamental pelos fenômenos próprios de um conjunto de viventes constituídos em população: saúde, higiene, natalidade, longevidade, raças... Sabe-se o lugar crescente que esses problemas ocuparam desde o século XIX e que desafios políticos e econômicos eles vêm constituindo até hoje” (FOUCAULT, 2008, p. 431).
\end{abstract}

Nesta citação do filósofo francês destaca-se a racionalidade que se percebe nas ações de controle social: há uma lógica que se impõe sobre os seres, tanto em seus corpos individuais quanto em sua condição de um único corpo social, constituído em população. Essa espécie de racionalização das ações governamentais liga-se a um exercício de governo e, para Foucault, nasce dentro do Liberalismo.É, pois, uma prática governamental constituída por fenômenos que dizem respeito aos seres vivos em sociedade.

Se, por uma perspectiva, as formas de ordenamento ou disciplina são aceitas e, inclusive, desejadas pela população - como, por exemplo, os direitos humanos, as políticas de saúde e educação, a segurança e o bem-estar coletivo -, por outra perspectiva, cabe pensar: quem é incluído ou não nessas formas de ordenamento ou normatização social? Como esse ordenamento atua, contra ou a favor da autonomia dos indivíduos que compõem a população? Sob qual pensamento se institui o que deve ser obedecido, o que se cristaliza como verdade, exemplo ou conduta legal? O que representa a postura de ir contra ao que se define como correto, bom, melhor ou legal?

Dessa forma, a biopolítica - política da vida ou política pensada para agir sobre a vida humana em sociedade - é, como propõe Foucault, uma relação bastante complexa "de exterioridade e de interioridade" entre os seres e o Estado (FOUCAULT, 2008, p. 433-434). Nessas interrelações sociais é que se afirmam as formas desse poder regulador.

Em seus estudos que dialogam com a obra de Foucault, o filósofo italiano Roberto Esposito (2010) também reflete sobre a biopolítica, compreendendo-a como as vidas individuais integradas à vida da espécie humana e divididas, por meio de censuras internas, em zonas de diferente valor social. Nessa reflexão, pode-se notar o envolvimento das divisões individual e coletiva da vida humana, a imposição de limites e regras - ou censuras - dentro das interrelações sociais 
e a categorização dos seres em determinadas escalas de valor, a depender de sua inserção ou não dentro da sociedade.

Em relação à classificação dos seres sociais, de acordo com uma maior ou menor adequação deles às formas de controle, Esposito discute a presença da morte como mecanismo de controle praticado pela biopolítica. De acordo com Esposito, para a pergunta "[...] porque é que, pelo menos até hoje, uma política da vida ameaça sempre transformar-se numa obra de morte?” (ESPOSITO, 2010, p. 23). A resposta seria porque "as questões de vida e de morte [...] já não dizem respeito a áreas singulares, mas ao mundo em toda a sua extensão" (ESPOSITO, 2010, p. 30), atenuando-se as distinções entre o externo e o interno, entre o particular e o público. Por isso, para este filósofo, o papel decisivo do poder não é o da "regulação entre os indivíduos, ou entre eles e o poder, mas sim o da sua sujeição a um determinado ordenamento ao mesmo tempo jurídico e político" (ESPOSITO, 2010, p.47). A biopolítica, então, poderia ser compreendida como ações de controle dos indivíduos, com vistas a que cada um seja enquadrado como parte de um corpo social coeso, saudável, socialmente fortalecido, padronizado com partes que se reconhecem iguais, dóceis e produtivas. Ou seja: seres controláveis que, no fundo, são peças de uma engrenagem que utiliza a força vital e intelectual dos corpos dóceis para a manutenção de um status quo definido por forças de poder, para a produção de bens e discursos, para a padronização de comportamentos; por esse controle, tudo o que não cabe nos limites do aceitável, deve ser extirpado.

Por isso, em contrapartida, cabe questionar sobre os corpos que por vários aspectos não se enquadram nos ajustamentos sociais estipulados pelo poder regulador que controla as formas de vida em uma sociedade. Esses corpos incomuns são uma espécie de ameaça ao controle, marcados pela doença, pela deformidade e outras formas de exposição estética da diferença. Contudo, se para o enaltecimento da vida biológica, os corpos devem ser produtivos, cabe pensar: a que lugar são relegados os que não podem ser produtivos no formato de produção capitalista, por exemplo? Qual vida o Estado promoverá ou permitirá que viva? Qual deixará morrer? E o que representa as vidas que se colocam, estética e politicamente, fora dessas amarras?

As respostas a esses questionamentos podem ser vistas nos corpos humanos que ocupam o caótico espaço urbano: para uns, vida supostamente plena - já que também não são de todo livres; para outros tantos, a morte, pensada aqui não como processo natural de cada ser vivo, mas como projeto político, forma de descarte de vidas ou, como se percebe nas novelas de Bellatin, uma saída diante da imposição de formas de vidas humanas que não se pretende seguir.

São esses corpos insólitos que se mostram na obra de Bellatin: seres não se circunscrevem plenamente no exercício de sua cidadania e, enquanto vivem, por vezes, mal podem suprir as necessidades básicas para continuarem vivendo; por seu caráter de diferença, suas singularidades são postas em categorias de menor prestígio social e de desconsideração; eles ocupam esferas da vida que os submetem 
a contornos de animalidade por meio de classificações externas; a contrapelo, são eles as presenças que incomodam esse poder.

Para melhor compreensão sobre o lugar da diferença no qual os corpos não adequados/adestrados se situam, as vidas social e natural poderiam ser investigadas como categorias para se pensar sobre inserção e exclusão. Essa distinção - mas não uma separação - entre duas significações para o conceito de vida, classificadas por meio da dicotomia entre zoé e bíos, são categorias aristotélicas problematizadas posteriormente por Giorgio Agamben (2007). Para Agamben,

\footnotetext{
Os gregos não possuíam um termo único para exprimir o que nós queremos dizer com a palavra vida. Serviam-se de tais termos, semântica e morfologicamente distintos, ainda que reportáveis a um étimo comum: zoé, que exprimia o simples fato de viver comum a todos as seres vivos (animais, homens ou deuses) e bíos, que indicava a forma ou maneira de viver própria de um indivíduo ou de um grupo (AGAMBEN, 2007, p. 09)
}

Compreende-se zoé, por meio do pensamento grego, como a vida natural que é experimentada por todos os viventes. Em seus domínios, estão as ações que nos igualam aos animais: a necessidade de alimentação, de excreção, de reprodução, entre outras. Esse seria um modo de vida no qual não haveria a liberdade de escolha, uma vez que não se pode reprimir aquilo que é essencial para a manutenção da vida. Por outro lado, no espaço do instinto, há a irracionalidade e o não controle, algo definitivamente preocupante quando o que se deseja é a submissão das vidas aos ordenamentos de um poder.

Em outra face da vida humana está a bíos, que é a experiência individual ou do grupo social no qual o indivíduo está inserido, com as camadas de moral, de valores, de controle, de inserção ou de exclusão. É onde se compreende a vida racionalizada. Para Esposito (2010), a etimologia da palavra bíos não designa apenas a vida natural ou física, mas também e, igualmente significativa, a vida cultural. Esta designação exprime as relações de dependência da vida para com o Estado, que assume o papel de árbitro ou de mediador.

As duas formas de compreensão das existências humanas podem habitar o mesmo indivíduo. No entanto, para que os seres possam ser considerados socialmente dentro de um controle, como parte integrante da sociedade, é preciso distanciar-se da condição zoé - ou, pelo menos, mantê-la afastada do âmbito coletivo -, pois ela seria algo relativo ao que resta, por isso permanece em relação à perspectiva do poder como alguma coisa que deva ser desprezada, assim como serão desprezados aqueles e aquelas não reconhecidos por suas inserções na bíos do corpo coletivo.

O incômodo estaria na incapacidade de controlar e utilizar os corpos que sobrevivem fora dos padrões da suposta normalidade; esses que se incluem apenas em uma aproximação com o âmbito da natureza, como seres animalizados ou instintivos. Assim, os seres humanos que estão, por sua exclusão, mais inseridos 
na condição zoé - mesmo que atravessados por camadas de cultura e de técnica, pois talvez seja inconcebível a ideia de uma vida totalmente natural sobrevivendo em meio a um contexto social - não possuem o mesmo valor e são impedidos de participar da vida coletiva em sua plenitude. São vistos como algo vergonhoso, ameaçador, que expõe insegurança, representando e apresentando a impossibilidade de controle, de homogeneidade, de dignidade. Vistos por um determinado prisma, esses corpos expõem a fragilidade das relações e mecanismos de manutenção das sociedades. Por isso são, por vezes, sumariamente destruídos ou, enquanto vivem, carregam o asco, o pavor e o incômodo de outrem sobre suas peles. Portanto, o que pode ser considerado como vida depende de quem tem o poder de validar essa espécie de vida. Sobretudo os corpos marcados pela diferença dos padrões estéticos, raciais, sociais e morais são alvos maiores dos instrumentos da biopolítica para instituir métodos e condições com os quais o poder consegue matar.

A respeito dessa relação entre a morte e a biopolítica, Achille Mbembe (2016) formula o termo necropolítica, para designar a capacidade do poder em fazer viver ou deixar morrer por meio de um conjunto de políticas de controle social. De acordo com Mbembe, o poder teria a condição "de definir quem importa e quem não importa, quem é 'descartável' e quem não é” (MBEMBE, 2016, p. 135). Ao enfraquecer as vidas, pode-se "determinar o valor das pessoas e julgar seu valor e utilidade”. (MBEMBE, 2016, p. 141). Mbembe afirma ainda que, quando o valor e a utilidade do ser não são demonstrados, esses são enquadrados em categorias de menor relevância social, por vezes, como formas de morte em vida. Há, assim, o estabelecimento de uma relação desigual relacionada com a desigualdade do poder sobre a vida. Nesse ponto, a humanidade de uma pessoa é anulada.

Quanto aos corpos não adaptados acabam por serem relegados à condição de exclusão e, mesmo quando permanecem vivos e habitam um espaço social urbano e caótico, esses corpos estão - como vida nua - próximos à condição da zoé. Portanto, ameaçam a ordem. Esse conceito de vida nua foi problematizado por Giorgio Agamben que, ao utilizar um termo do direito romano, o compreende como uma vida matável, mas que não pode ser sacrificada. Esse conceito não se estabelece por meio do valor real de um indivíduo ou por subjetividades de outras categorias. É por intermédio de um ordenamento político e jurídico que a vida humana é classificada, ordenada, incluída ou descartada.

Para Agamben (2012, p. 119), há uma relevante preocupação da biopolítica em assegurar o controle, o cuidado e o usufruto da vida nua, ou seja, de uma vida totalmente desamparada, um rastro ou signo presente de uma vida já ausente, como um resto de uma vida política. Estando sobre o julgo e o controle do poder, essas vidas nuas receberiam a destinação mais adequada a esse mesmo poder. Um exemplo disso seria o caso de uma doença ameaçadora: os corpos enfermos não poderiam, dentro das leis, serem mortos. Mas a exclusão de acesso ao atendimento de saúde, ao medicamento e a construção de discursos que os transformam em perigo iminente, fazem com que eles sejam como párias dentro de seu próprio país. Viveriam 
em condição exílica interna - que também é uma forma de segregação -, mesmo que, oficialmente, deles não se tenham retirados os direitos civis. Dessa forma, a morte seria como atenuada pelo bem comum e não haveria a culpa ou o arrependimento por tais perdas, já que o bem comum estaria acima do bem individual; e as existências humanas transformadas em vidas nuas poderiam ser matáveis. Essa distinção assume, para Agamben, uma posição central em sua teoria, pois para ele

A dupla categorial fundamental da política ocidental não é aquela amigo-inimigo, mas vida nua-existência política, zoé-bíos, exclusão-inclusão. A política existe porque o homem é o vivente que, na linguagem, separa e opõe a si a própria vida nua e, ao mesmo tempo, se mantém em relação com ela numa exclusão inclusiva. (AGAMBEN, 2007, p. 16)

O conceito de vida nua para se referir ao homo sacer foi utilizado por Agamben (2007), em suas reflexões sobre as vítimas da shoá que tiveram suas vidas ceifadas nos campos de concentração nazistas. $\mathrm{Na}$ atualidade, esse conceito de vida nua também poderia ser pensado em outras situações, sempre que a vida humana fosse precarizada de tal forma que dela se retirasse seu direito de cidadão. Essas manipulações da vida pelo poder garantem o ordenamento, a vigilância e destinam à morte aqueles que no momento histórico estão em desacordo com as vontades ou os projetos do poder, pois para Agamben, "o rio da biopolítica corre de modo subterrâneo, mas contínuo” (AGAMBEN, 2012, p. 118). No fluxo contínuo da história, há uma certa normalidade na exclusão de algumas vidas, mesmo que essa exclusão seja construída sorrateiramente.

Em outras categorias de vida nua, estão os corpos que experienciam um desajuste quanto às expectativas do ordenamento social. Alguns desses corpos serão investigados por meio de sua presença como personagens de textos literários do escritor mexicano Mario Bellatin.

\section{Corpos insólitos na insistência do existir: relações entre literatura e biopolítica em textos de Mario Bellatin}

A literatura, como arte e, por isso mesmo, como linguagem, é capaz de manter uma relação dialógica com a realidade na qual se insere. Pode, dessa forma, percorrer questões atuais, repensar os fatos históricos e tecer projeções para um porvir, em várias camadas de diferentes áreas do conhecimento. Tendo essa abertura para atravessar, por seus caminhos ficcionais, as sendas entre arte e sociedade, a literatura possui um caráter de liberdade que a situa em um estrato no qual se pode, inclusive, questionar os liames que a conectam com a vida. Para Jacques Derrida:

O espaço da literatura não é somente o de uma ficção instituída, mas também o de uma instituição fictícia, a qual, em princípio, permite dizer tudo. Dizer tudo é, sem dúvida, reunir, por meio da tradução, todas as 
figuras umas nas outras, totalizar formalizando; mas dizer tudo é também transpor [franchir] os interditos. É liberar-se [s'affranchir] - em todos os campos nos quais a lei pode se impor como lei. A lei da literatura tende, em princípio, a desafiar ou a suspender a lei. Desse modo, ela permite pensar a essência da lei na experiência do "tudo por dizer”. É uma instituição que tende a extrapolar [déborder] a instituição. (DERRIDA, 2018, p. 49)

Ao extrapolar as instituições e o instituído, estabelece-se pela arte literária uma ideia de democracia em cujas páginas se organizam outras formas de conexão e de reflexão sobre a vida e os seres. Dito isso, é preciso compreender, nessa relação entre ficção e realidades: de que maneira o externo, que é a realidade, se inter-relaciona com o dentro, que é a proposição da arte. Mesmo que a literatura não tenha um caráter documental, o material com que se compõe - que é a linguagem - transita em todos os campos da vida humana. É por meio da linguagem que a literatura estabelece diálogos, de forma rizomática, com áreas do conhecimento distintas. A literatura atravessa também os domínios da biopolítica. Para o objetivo proposto nesse texto, utiliza-se a literatura - nesse caso, a arte literária produzida pelo escritor Mario Bellatin - como espaço de problematização dos aspectos concernentes ao controle social sobre a vida de corpos fora dos padrões, principalmente, como propõe Derrida, no sentido de "transpor os interditos" das relações de poder. Em relação às personagens das duas novelas de Bellatin, cabe refletir sobre como a presença dessas vidas está em uma postura contrária à força desse biopoder.

Sendo a arte uma instância capaz de problematizar a realidade em seus múltiplos prismas, delimita-se para a análise das personagens de Bellatin: o questionamento da condição de vida, entre (não) relevância, (não) serventia e destinação dos corpos marcados pela diferença física; o fato desses seres não fazerem parte dos processos de produção e de consumo tão caros à manutenção do paradigma capitalista; a presença, no mesmo cenário urbano, desses corpos que ultrapassam limites comportamentais e estéticos, colocando-se, na questão política, como ameaça ao ordenamento social, que contemplaria somente os corpos produtivos (saudáveis, inteiros, capazes física e intelectualmente de produzir) e os corpos que são conservadores de nossa espécie (quando se pensa sobre sexualidade, gênero e reprodução humana).

Os corpos destacados nas duas novelas de Mario Bellatin, Salón de Belleza (2005) e Los fantasmas del masajista (2006) não estão sob as amarras das normas e dos modelos comportamentais impostos. Nelas aparecem corpos de excluídos especialmente, por doença, homossexualidade ou deficiência física - e o incômodo social provocado por suas existências. Nelas, o que parece se apresentar como recusa não é somente o lugar de plena cidadania aos corpos divergentes, mas é a própria interlocução desses corpos com o poder, uma vez que essas vidas se recusam a fornecer a resposta ou explicação exigida pelo poder para o fato de existirem.

Nas vidas dessas personagens há que se pensar sobre aspectos estéticos, médicos e políticos nos corpos enfermos, amputados, "montados" em ornamentos e maquiagens, corpos sem vida ou com vidas atravessadas pelos instrumentos de 
controle do poder que instituem comportamentos e formas corporais dentro de uma noção de normalidade, excluindo ou deixando morrer as vidas cujos corpos são destacados pela diferença de suas materialidades.

O primeiro deles, Salón de Belleza (2005), apresenta corpos destinados à morte. O título sugere um espaço de cuidados pessoais, um estabelecimento comercial destinado a técnicas ou tratamentos estéticos que buscam aprimorar a aparência, os cabelos, as unhas, a pele das pessoas. Mas, no texto de Bellatin, esse lugar se converte em um "moridero", para onde vão aqueles que foram contagiados por uma espécie de doença, chamada apenas de o "mal". Nesse lugar, os corpos contagiados teriam amparo necessário apenas para seus últimos dias. No "moridero", é permitido apenas "que las familias aporten dinero, ropa y golosinas. Todo lo demás está prohibido" porque é desnecessário ao pouco tempo que lhes resta. (BELATTIN, 2005, p. 07).

Sobre a doença, não se nomeia o mal nem as pessoas doentes, mas dá-se a entrever uma analogia com a identificação da AIDS no início dos anos 80 e a exclusão social dos homossexuais afetados por ela. O salão de beleza "situado en un punto tan alejado de las líneas de transporte público” (BELLATIN, 2005, p. 12), recebia aqueles que eram recusados pelos hospitais por "temor a que estuviesen contagiados" (BELLATIN, 2005, p. 07).

A exclusão desses corpos contagiados aponta para uma questão política que é a imunização do corpo coletivo: os organismos afetados pela doença - especialmente por uma enfermidade desconhecida, para a qual não se tem o controle da ciência - serão organismos apartados. Suas vidas restringem-se ao pouco tempo que resta. Nesses corpos doentes, esvazia-se a humanidade. Como um resto social, são destinados à morte isolada, sem ritos e sem a presença dos seus. Assim, esses corpos doentes se conservam, enquanto ainda respiram, distantes dos olhos e das consciências - ou da piedade alheia - dos não doentes, que seguem normalmente suas vidas, como se nada houvesse, até que também sejam eles próprios contaminados e sumariamente excluídos.

A doença se torna, nessa novela de Bellatin, um elemento relevante para a análise, sobretudo, quando se pensa a respeito do tema da imunização do corpo político. Sobre isso, Esposito afirma que "a imunidade não é apenas a relação que liga a vida ao poder, mas o poder de conservação da vida” (ESPOSITO, 2010, p. 74). Dessa forma, as vidas são controladas e selecionadas pelo poder que: ou a nega ou proporciona seu desenvolvimento; ou a exclui ou a protege; ou permite suas subjetividades - dentro do tolerável - ou as padroniza, dentro de normas sociais. Para Esposito, é uma questão de autopreservação imunitária, pois “todos os dispositivos do saber e do poder desempenham um papel de contenção protectora em relação a uma potência vital voltada a expandir-se ilimitadamente" (ESPOSITO, 2010, p. 76).

Os corpos contaminados dessa novela de Bellatin contém em si essa potência vital e, ao mesmo tempo, a iminência do contágio. Distantes das políticas de infraestrutura urbana, recusados pelo sistema público de saúde, pelas famílias, pela sociedade, desses corpos doentes - também por sua condição de homossexuais 
- são retiradas suas individualidades, tornavam-se iguais em sua condição de exclusão e já "no son más que cuerpos en trance de desaparición” (BELLATIN, 2005, p. 13). Cada um deles se torna, assim, apenas "un cuerpo más al que había la obligación de eliminar" (BELLATIN, 2005, p.14). O desamparo social a que são relegados esses corpos doentes corroboram a reflexão de Esposito, quando diz que, na biopolítica, "não é só a morte a atacar a vida, mas a própria vida a construir o mais virulento instrumento de morte" (ESPOSITO, 2010, p. 212). Em outras palavras, os corpos contagiados, não são mortos, mas são expostos ao nada social. Nesse sentido: vivem?

O corpo fragilizado do doente, especialmente nesse caso de doenças que disseminam medo e distanciamento - como a AIDS - representa, pela lógica do poder disciplinar, um perigo à vida coletiva. O medo do contágio sustenta a aceitação da suspensão dos direitos, tornando-os desamparados. São uma espécie de "vida nua”, pois, no conceito de Agamben (2007), essa categoria de vida seria "matável”. Mesmo que na novela Salón de Belleza não seja apresentado um assassino ou um instrumento material para matar, a morte do corpo doente se dá, em primeiro plano, como morte social dos seres que se encontram desprovidos de camadas da bíos.

A questão da sexualidade na novela - especialmente no que diz respeito à homossexualidade - marca um lugar antagônico compreendido socialmente como ameaçador. A sexualidade, que é interesse central da biopolítica, pode ser pensada tanto no âmbito particular, com a disciplina dos corpos, quanto no âmbito coletivo, por meio da regulação da população. Os corpos homossexuais na novela, quando em plenitude de saúde, mostravam-se em suas diferenças por intermédio de adereços, maquiagens e por frequentarem espaços urbanos marcados pelas qualificações de pecaminoso, furtivo e pouco recomendável, por isso, encobertos pela escuridão da noite ou pelo acesso restrito. Na novela, a presença dos homossexuais é vista pela população como incômoda por ser exposição intolerável ou provocação explícita ao estabelecimento do conjunto de normas aceitáveis socialmente. Esse conflito resulta em constantes atos de violência que são denunciados pelo narrador no seguinte excerto:

Tal vez salvarme de un encuentro con la Banda de los Matacabros, que rondaba por las zonas centrales de la ciudad. Muchos no sobrevivían a los ataques de esos selvajes, pero creo que si después de un enfrentamiento alguno salía con vida era peor. En los hospitales donde los internaban los trataban siempre con desprecio. Muchas veces no querían recibirlos por temor a que estuviesen contagiados. Desde entonces, principalmente por las tristes historias que me contaban, me nasció la compasión de recoger a alguno que otro compañero herido que no tenía donde recurrir. Tal vez de esa manera se fue formando este triste Moridero que tengo la desgracia de regentar. (BELLATIN, 2005, p. 07)

O narrador se apresenta como os doentes sob seus cuidados: travesti e homossexual, ele também está contaminado. Em seu corpo a exposição de feridas, 
o aspecto decadente, pele e osso, as dores e diarreias causavam agora náusea e raiva nos clientes que ainda aparecia no "moridero".

Seguem-se na narração a comparação entre os peixes dos aquários que decoravam o salão e os que doentes chegam para morrer. No início, ambos - peixes e homens - exuberantes, coloridos e cheios de vida, com o brilho das escamas/ roupas e o viço da energia vital. No desenvolvimento da doença, o que se vê são poucos peixes em branco e preto, além de frágeis corpos à espera da morte. Ao comparar os corpos doentes aos peixes, o narrador diz que o desaparecimento de um peixe não importa a ninguém. Infere-se, portanto, que, da mesma forma, sem acolhimento nem afeto ou utilidade, a morte do portador do mal também não importaria a ninguém. Seria um alívio para a sociedade. Ele perderia somente sua vida natural, visto que a vida biológica já se extinguira antes da morte física.

A sexualidade aflorada nos corpos em início da contaminação se mantém no decorrer do mal, contudo transforma-se em uma espécie de desejo que liga os corpos à vontade de continuar vivendo. Se, por um lado, a sexualidade é instrumento de controle e disciplina dos corpos individuais e coletivos, por ela também se pode viabilizar formas de resistência à biopolítica ou ainda, inclusive no texto analisado, mais que resistência ao disciplinamento, há uma peculiar neutralidade e frieza diante do impedimento. Essa liberdade sexual exacerbada é que se mostra perigosa, por não ser indômita.

Foucault (1999) aponta que sobre o corpo - tanto em sua condição de máquina quanto de espécie - atua uma biopolítica da população, uma vez que "as disciplinas do corpo e as regulações da população constituem os dois pólos em torno dos quais se desenvolveu a organização do poder sobre a vida" (FOUCAULT, 1999, p. 131). Ao falar sobre a administração dos corpos e a gestão calculista da vida, Foucault afirma que o sexo é um instrumento de resistência ao biopoder, pois

Se, por uma inversão tática dos diversos mecanismos da sexualidade, quisermos opor os corpos, os prazeres, os saberes, em sua multiplicidade e sua possibilidade de resistência às captações do poder, será com relação à instância do sexo que deveremos liberar-nos. Contra o dispositivo de sexualidade, o ponto de apoio do contra-ataque não deve ser o sexo-desejo, mas os corpos e os prazeres. (FOUCAULT, 1999, p. 147)

Assim, na luta da vida contra a morte, ou de Eros contra a tanatopolítica, a vida ganha força na pulsão, no combate à morte e no desejo que os corpos têm de continuarem vivos. Isso se nota na novela de Bellatin quando, mesmo sendo um "moridero", do antigo salão de beleza "[...] emana aún algo de vida" (BELLATIN, 2005, p. 15), pois os corpos - em delírio ou sofrimento, "[...] se aferran de una manera extraña a la vida” (BELLATIN, 2005, p. 15). Possuíam, ao mesmo tempo, uma grande agonia, mas ainda tinham uma pequena energia vital. Continuavam a ser, portanto, símbolos de vida. 
Os corpos, homossexuais e doentes, queriam viver, apesar de não existir "una forma en que vean sus males atemperados" (BELLATIN, 2005, p. 16). Assim se estabelece uma luta entre duas forças: I) no âmbito da zoé - a vida natural, o instinto, a pulsão de vida - a vontade do doente em continuar a viver, mesmo que essa vida se restrinja a continuar respirando; II) no âmbito da bíos - um corpo que deveria ser reconhecido como vida, mas que representa um perigo iminente e, portanto, que deve ser ceifado para que o corpo coletivo se mantenha sob controle.

No segundo texto de Bellatin, Los fantasmas del masajista (2006), são apresentadas personagens cujos corpos são de pessoas "que han perdido o están por perder algún miembro" (BELLATIN, 2006, p. 587), "una serie de individuos con limitaciones físicas que parecen buscar [...] la paz que sus cuerpos dan la sensación de necesitar" (BELLATIN, 2006, p. 587). Dentre as personagens, há uma mulher que "apenas unos días atrás habían cercenado una pierna" (BELLATIN, 2006, p. 588). Na perna ausente, ou seja, na própria ausência, há uma dor profunda, um "sufrimiento que se producía en un espacio que era ahora ajeno a su cuerpo, en el lugar vacío que había dejado la pierna mutilada” (BELLATIN, 2006, p. 588). A dor que permanece em algo que foi amputado (individual ou coletivamente) pode ser pensada como a presença incômoda - da dor, dos seres - que deveria não existir, uma vez que foi extirpada, mas que insiste em se mostrar em sua ausência presente ou em sua presença fantasmagórica.

Há também nessa obra uma autoridade que elege "a parte" que será extirpada em benefício da saúde do corpo (coletivo?), bem como o uso de técnicas e conhecimentos da área médica. Em relação à inclusão do domínio da técnica na discussão sobre biopolítica e procedimentos éticos na medicina, seria relevante apresentar a consideração proposta por Roberto Esposito, ao ponderar sobre a interposição da técnica nas vidas politicamente construídas. Isso porque o domínio da técnica permite o domínio das vidas atravessadas por ela. Para Esposito,

[...] o corpo humano aparece sempre mais desafiado, e até literalmente atravessado, pela técnica. A política penetra directamente na vida, mas entretanto, a vida tomou-se outra coisa por si só. E então, se não existe uma vida natural que não seja, ao mesmo tempo, também técnica; se a relação a dois entre bios e zoé deve agora, ou talvez desde sempre, incluir como terceiro termo correlativo, a techne, como supor uma relação exclusiva entre política e vida?” (ESPOSITO, 2010, p. 31)

Os corpos mutilados ou amputados são corpos submetidos ao controle da técnica que, por sua vez, é controlada por um poder. Não se pode negar o atravessamento - no caso da medicina, até mesmo físico - da técnica nos corpos biopolíticos. No excerto da novela de Bellatin, pode-se destacar também a mutilação ou amputação dos corpos e a sensação de dor presente "en el lugar vacío" do membro inferior. 
Ao se extirpar uma parte do corpo humano, outras camadas se sentido se sobrepõem à discussão. Seria interessante observar o que Achille Mbembe pondera sobre amputação de partes do corpo humano e seu atravessamento pela técnica:

Em outros casos, em que a amputação física substitui a morte imediata, cortar os membros abre caminho para a implantação das técnicas de incisão, ablação e excisão que também têm os ossos como seu alvo. Os vestígios dessa cirurgia demiúrgica persistem por um longo tempo, sob a forma de configurações humanas vivas, mas cuja integridade física foi substituída por pedaços, fragmentos, dobras, até mesmo imensas feridas difíceis de fechar. Sua função é manter diante dos olhos da vítima - e das pessoas a seu redor - o espetáculo mórbido do seccionamento. (MBEMBE, 2016, p. 142)

Nesses corpos, muitas vezes são implantados recursos da técnica e do conhecimento científico, a fim de potencializá-los, recapacitando-os para o desenvolvimento de suas atividades cotidianas, mas, sobretudo, como corpos que podem se tornar mais produtivos em relação ao sistema de produção capitalista, como também esteticamente mais aceitos ou mais padronizados, de acordo com os modelos de corpos socialmente desejáveis. Dessa forma, as interposições dos reinos da natureza e da cultura, que antes poderiam ser percebidas nos constructos sociais e demais legados dos humanos em seu meio externo, agora podem, cada vez mais presentes, serem percebidas em seus próprios corpos.

Em seu texto sobre as mutações biotecnológicas dos corpos - que são também biopolíticas -, Paula Gaudenzi (2016) discorre sobre o que ela denomina como "tecnologias de incorporação" e chama a atenção sobre uma nova subjetividade biomédica que se constitui na contemporaneidade, com suas implicações na gestão da vida, na normalização dos corpos e em seus comportamentos, bem como a diluição das fronteiras entre biológico e tecnológico, entre normal e patológico. Gaudenzi assim denomina o termo tecnologias de incorporação, que seriam

\footnotetext{
aquelas tecnologias que são utilizadas no corpo e que podem se tornar parte dele, seja como objetos que são incorporados ao biológico, borrando a fronteira entre artefato e biologia, ou entre externo e interno; seja como objetos que são utilizados de tal forma que funcionam como inscrições de identidade. São eles: as próteses, os hormônios, os aparelhos auditivos, as cadeiras de rodas, "as tecnologias de melhoramento", entre outros. (GAUDENZI, 2016, s/p)
}

Assim, Gaudenzi afirma que os corpos permeados pela técnica a serviço da biopolítica mantem uma relação entre o físico e o artefato - ou entre as esferas da natureza e da cultura. Esses artefatos seriam os objetos externos aos corpos, mas produzidos por mãos humanas e incorporados como parte simuladamente natural, sob uma certa indicação de "normalidade cosmética” (GAUDENZI, 2016, s/p). 
Aqueles que não se enquadram por razões como a deficiência física ou os padrões de beleza, as formas de controle social se encarregariam de eliminar.

Como os corpos homossexuais e enfermos da novela Salón de Belleza, os corpos amputados de Los fantasmas del masajista também conservam um desejo de viver (ou de ter seu corpo completo vivo) por meio da dor fantasma. Essa dor é sentida em um membro que não está mais, que foi extirpado, mas que ainda insiste em ser sentido, ou seja, é pelo inconsciente do ser, pela sua camada de subjetividade, que a "presença" ausente do membro amputado se interpõe entre o poder da técnica sobre os corpos e o desejo desse corpo. Interpõe-se em duplo sentido: a dor fantasma insere a lembrança da parte cortada, de certa forma, recolocando-a no corpo; e contrapõe-se ao poder de seccionar o corpo. A dor fantasma é presença pulsante da vontade de vida.

Mescla-se a essa história a presença da morte de uma idosa, declamadora de músicas brasileiras. Com a chegada da morte, constata-se as fases da vida produtiva dessa mulher: do esplendor da fama na juventude ao declínio e isolamento na ancianidade. Os corpos idosos aparecem nos discursos sociais, muitas vezes, como fardos a serem carregados ou como prejuízos aos cofres públicos, já que a longevidade - que deveria ser entendida por seu caráter de conservação e bem-estar da vida humana -, é destacada por não incluir mais os idosos na camada produtiva da população, levando-se em conta a produção nos termos capitalistas. Um exemplo disso, encontra-se nas palavras do ministro da Economia, Paulo Guedes, que, em abril de 2021, considerou que o Estado brasileiro não dá conta de suprir os recursos destinados à saúde pública, porque, segundo ele, o setor não estaria capacitado para atender à longevidade da população e que, portanto, o Estado não teria a capacidade de investir em atendimento médico, uma vez que as pessoas insistem em viver; e ainda, nas palavras do ministro: “Todo mundo quer viver 100 anos, 120, 130" (KUHL, 2021). Assim, na perspectiva do projeto político vigente no Brasil, menos idosos, representaria mais economia aos cofres públicos. Essa postura do governo brasileiro está de acordo com uma política que regula a vida humana e tem sobre ela, olhos atentos e controle, com discursos e ações.

Voltando à novela de Bellatin e à questão dos idosos (longevidade x produtividade), mesmo com a morte da senhora, seu papagaio passa a reproduzir seu discurso: ele canta a música por ela antes cantada; esse som produzido pela ave reverbera como uma presença fantasmagórica que marca uma (re)existência incômoda. Podese interpretar esse fato como a permanência (dos discursos, da memória), mesmo após a morte física. Outra pulsão de vida que teima em ainda estar.

Acrescenta-se a essas duas personagens - a senhora cuja perna foi amputada e a idosa morta -, um narrador que nasceu sem um dos antebraços - assim como, na realidade, é a condição física do escritor Mario Bellatin. O narrador possui a saúde fragilizada por outras doenças adquiridas e a cada dia se vê "más contrahecho e disforme", com seu físico se convertendo em "una masa irreconosible" (BELLATIN, 2006, p. 601). 
Assim, interessa pensar, especialmente, nesses três corpos marcados fisicamente: a mulher com sua dor fantasma; a presença fantasmagórica da senhora morta na reprodução de sua fala por seu papagaio; e um narrador, que por si, é uma presença fantasmagórica no texto.

O fantasma poderia ser pensado como uma re(existência) que se faz sentir, que insiste em permanecer. Esses seres, rotulados por serem "estorbo del cuerpo" (BELLATIN, 2006, p. 601), poderiam ser ressignificados, a partir de uma perspectiva dos que estão à margem social, como território de reflexão sobre conceitos éticos, médicos, políticos e econômicos. A expansão para além dos limites físicos do corpo está no fantasma: ele se expande em algo não controlável.

O fato de o membro amputado ainda doer, nos faz pensar nos limites do corpo físico e social. Além disso, se para um biopoder os corpos necessitam ser produtivos, ou seja, transformar-se em máquinas de produzir - entendendo-se produção dentro dos valores do capitalismo - como pensar em corpos mutilados, amputados, idosos, se não pela ideia de descarte ou de exclusão? E como pensar no desejo de vida/ na pulsão de vida desses corpos, se não pela possibilidade de se fazer empecilho, obstáculo, recusa à morte e, portanto, aos ditames do poder?

Esses corpos insólitos não necessariamente precisam ser compreendidos apenas por meio da construção biopolítica de suas imagens e de suas valorizações. Podem também serem compreendidos como vidas que, com sua presença ou insistência em continuar presente, são ameaças ao sistema, ao poder. Poderiam ser pensados como na imagem proposta por Georges Didi-Huberman (2011) ao refletir sobre a luz que emana do corpo pequeno e sensível do vagalume. Nesse animal, a luz é intermitente e delicada; não é capaz de apagar a grande luz maior que se sobrepõe à vida. Contudo, por sua insistência em sobreviver, o vagalume se faz presença perceptível; seu brilho também é visto; de sua existência emana algo de luz que também emite luminosidade. Qual o poder de vários vagalumes (corpos indóceis ou desviantes) diante da grande luz?

Assim são esses corpos insólitos inseridos na vida coletiva: são como os vagalumes sugeridos por Didi-Huberman cujas luzes intermitentes produzem formas de resistência diante da grande luz do poder que controla e oprime. Quanto à luz do vaga-lume, que é pequenina e fugaz, ela demonstra também uma postura corajosa e um posicionamento autônomo, por isso resiste e incomoda a luz maior.

Quanto ao vagalume, Didi-Huberman fala sobre o fascínio que a grande luz da biopolítica - exerce sobre as formas de vida, atraindo-as para a morte. Ao citar Pier Paolo Pasolini, Didi-Huberman diz que “o 'verdadeiro fascismo' [...] é aquele que tem por alvo os valores, as almas, as linguagens, os gestos, os corpos do povo. É aquele que 'conduz, sem carrascos nem execuções em massa, à supressão de grandes porções da própria sociedade.” (2011, p. 29). Contra esse mal - disfarçado no controle da biopolítica - o filósofo apresenta duas grandes armas de luta: coragem e poesia. Em relação aos corpos insólitos, a coragem os aferra à vida. Sobre a escrita de Bellatin, coragem e poesia são sinônimos de sua obra. 


\section{Conclusão}

A gestão calculada da vida se ramifica dentro de uma sociedade, divide e classifica os indivíduos de uma população, transformando-os em sujeitos, que, na compreensão de Foucault (1999), vistos por meio de uma perspectiva biopolítica, são efeitos de um discurso, constructo das técnicas individualizantes, por isso assujeitados. Dessa forma, a vida administrada por regimes de governabilidade descobre o indivíduo e o classifica como um corpo que deve ser adestrado, tornado dócil e produtivo. Nesse sentido, a eliminação ou a sobrevivência dos corpos passará por critérios de uma política disciplinar, que legisla sobre a conceituação de sujeito e nação, mantendo o exercício do direito de deixar viver ou decretar a morte. Dessa forma, a biopolítica é indispensável ao desenvolvimento do capitalismo. Por seu intermédio há a inserção dos corpos de maneira controlada. O controle, na contemporaneidade, adquire contornos cada vez mais amplos, inclusive virtualmente por meio dos algoritmos, estatísticas e acesso às informações. Dentro dessa lógica, o que se pretende é a disciplinarização dos corpos e uma regulação da vida humana; os que não se enquadram são as principais vítimas da exclusão em vida ou da morte, apresentadas dentro dos conceitos de tanatopolítica, ou necropolítica, conforme Mbembe.

Contudo, mesmo dentro das ramificações do poder, que se sustenta nas interrelações sociais, a literatura pode ser um discurso capaz de oferecer brechas e possibilitar o deslocamento da perspectiva, para que se veja, para além do que se expõe, outras nuances ou faces do corpo social coletivo. Talvez seja possível pensar a literatura como sugere Georges Didi-Huberman (2011), quando, ao citar Agamben, compreendendo-a como tarefa que exige "coragem - virtude política - e poesia, que é a arte de fraturar a linguagem, de quebrar as aparências, de desunir a unidade do tempo" (DIDI-HUBERMAN, 2011, p. 70).

A produção literária do escritor mexicano Mario Bellatin cumpre esse papel. Os corpos de suas personagens, postos à margem, sem a plenitude de sua condição de cidadão, à mercê de sua própria sorte - são como os corpos humanos que compõe os grupos minoritários, no sentido da exclusão de seus discursos nas camadas do poder, de suas vozes nas criações epistemológicas ou de suas presenças físicas nas etapas de produções e consumos.

Muitas vezes - e com mais frequência na atualidade -, corpos como os que aparecem nas páginas de Bellatin são utilizados em discursos publicitários ou políticos, como uma forma de sugerir a inclusão; contudo, continuam a ser inseridos apenas dentro desse discurso ou estratégia que induz uma suposta equidade, mas que sustenta (ou suporta) a diferença somente quando transformada em possibilidade de consumo, de lucro, de controle. Por isso, considera-se nesse texto que o escritor não se dobra a esse engodo, que seu texto faz questão de expor o incômodo da presença e, com ela, nos faz refletir sobre a questão da vida dentro da esfera biopolítica.

Na possibilidade de "transpor os interditos", como propõe Derrida, está a literatura de Mario Bellatin. Ela se converte em texto necessário, porque é necessária a arte que pode provocar nos seres um movimento em direção a uma 
conscientização da inserção humana dentro dos sistemas de poder. Essas duas novelas de Bellatin - Salón de beleza e Los fantasmas del masajista - brilham como a luz do vagalume pensado por Didi-Huberman, pois, em sua intermitência, são capazes de chamar a atenção dos olhares antes resignados a apreciar somente um ponto de luminosidade.

\title{
THE UNUSUAL BODY AND BIOPOLITICS IN MARIO BELLATIN'S TEXTS
}

\begin{abstract}
The article discusses the political relations experienced by the bodies presented as misshapen or different, present in the works Salón de Belleza (2005) and Los fantasmas del masajista (2006), by Mario Bellatin. They are diseased, adorned, mutilated or made-up bodies that escape the established standards and constitute a place of existence and of non-adaptation of socially imposed models. Their relationship with collective life will be a territory for reflection on ethical and political concepts. This condition of the bodies will show the approximation of certain lives to the concept of naked life. The analysis is based on studies on biopolitics and uses, as a theoretical basis, Michel Foucault (1999; 2008), Giorgio Agamben (2010), Georges Didi-Huberman (2011), Roberto Esposito (2010) and Achille Mbembe (2016).
\end{abstract}

Keywords: Literature; Biopolitics; Body; Mario Bellatin.

\section{Referências}

AGAMBEN, Giorgio. Homo Sacer: o poder soberano e a vida nua I. Tradução de Henrique Burigo. 2. reimp. Belo Horizonte: Editora UFMG, 2007.

BELLATIN, Mario. Salón de belleza. Buenos Aires: Eloiza Cartonera, 2005.

BELLATIN, Mario. Los fantasmas del masajista. In: BELLATIN, Mario.

Obra reunida. Madrid: Alfaguara, 2006. p. 586-601.

DERRIDA, Jacques. Essa estranha instituição chamada literatura. Uma entrevista com Jacques Derrida. Tradução de Marileide Dias Esqueda. Belo Horizonte: Editora UFMG, 2014.

DIDI-HUBERMAN, Georges. Sobrevivência dos vaga-lumes.

Belo Horizonte: Editora da UFMG, 2011.

ESPOSITO, Roberto. Bios. Biopolítica e filosofia. Tradução de M. Freitas da Costa. Lisboa: Edições 70, 2010.

FOUCAULT, Michel. Nascimento da biopolítica. Curso dado no College de France (1978-1979). Tradução de Eduardo Brandão. São Paulo: Martins Fontes, 2008.

FOUCAULT, Michel. História da sexualidade - I A vontade de saber. 13. ed. Tradução de Maria Thereza da Costa Albuquerque e J. A. Guilhon Albuquerque. Rio de Janeiro: Graal, 1999. 
GAUDENZI, Paula. Mutações biopolíticas e discursos sobre o normal: atualizações foucaultianas na era biotecnológica. Interface (Botucatu) vol. 21. no. 60. Botucatu jan./mar. 2017. Epub 20-Out-2016. Disponível em: https://www.scielo.br/scielo. php?script=sci_arttext \&pid=S1414-32832017000100099\&lng=pt\&tlng=pt. Acesso em jul. 2020.

KUHL, Natália. Longevidade é ruim para os cofres, diz Guedes: “Querem viver 100 anos”. Metrópoles. Disponível em: https://www.metropoles.com/brasil/ longevidade-e-ruim-para-os-cofres-diz-guedes-querem-viver-100-anos. Acesso em jun. 2021.

MBEMBE, Achille. Necropolítica. In: Arte \& Ensaios: Revista do PPGAV - EBA/ UFRJ. n.32. dez. 2016. p. 123-151. Disponível em: https://revistas.ufrj.br/index. php/ae/article/view/8993. Acesso em 20 jul. 2020.

SARAIVA, Francisco Rodrigues dos Santos. Novíssimo Dicionário Latinoportuguês. Rio de Janeiro/Belo Horizonte: Livraria Garnier, 2000.

Recebido em 15 de abril de 2021 Aprovado em 12 de junho de 2021 